\title{
A new approach for reducing pollutants level: a longitudinal cohort study of physical exercises in young people
}

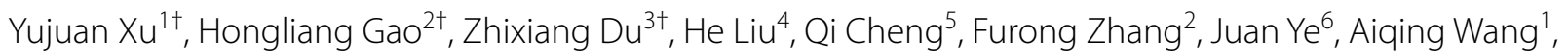
Yanjun Dou ${ }^{1}$, Bei Ma ${ }^{1}$, Ningwei Zhao ${ }^{7}$, Feng Zhu ${ }^{4^{*}}$, Xianlin $\mathrm{Xu}^{8^{*}}$, Ning Shen ${ }^{9^{*}}$, Jing Wu ${ }^{2^{*}}$ and Bin Xue ${ }^{2^{*}}$

\begin{abstract}
Background: The present study aimed to evaluate the elimination of three common pollutants (dimethoate, benzo(a)pyrene (BaP) and bisphenol A (BPA) by different physical exercises and to assess the possible factors which could affect the pollutants elimination.

Methods: A total of 200 individuals who chose different kinds of exercises in accordance to their own wish were recruited. The levels of urinary pollutants were measured using $\beta$-glucuronidase hydrolysis followed by a high-performance liquid chromatography tandem mass spectrometry-based method.

Results: Totally, the levels of dimethoate, BaP and BPA were reduced after physical exercises. However, the elimination of $\mathrm{BaP}$ in male was higher than that in female but the elimination of BPA in female was higher than that in male. Multivariate logistic regression showed that the degree of heart rate (HR) change was a protective factor affecting the improvement effect of dimethoate, BaP and BPA while BMI (body mass index) was a risk factor. Nevertheless, sex was a risk factor affecting the improvement of dimethoate and BaP but had a lower efficacy on BPA improvement.

Conclusion: The present findings indicate that physical exercises can be considered as a novel approach to eliminate pollutants level in human body and can also give suggestions for choosing specific physical exercises to male and female individuals. Moreover, those who are with higher BMI need to lose weight before eliminating pollutant level through physical exercises.
\end{abstract}

Keywords: Environmental exposure, Physical exercise, Elimination of pollutants, Dimethoate, BaP, BPA

\section{Introduction}

*Correspondence: xuebin@njmu.edu.cn

†Yujuan Xu, Hongliang Gao and Zhixiang Du contributed equally to this work.

${ }^{2}$ Core Laboratory, Sir Run Run Hospital, Nanjing Medical University, Nanjing 211166, China

${ }^{4}$ General surgery department, Sir Run Run Hospital, Nanjing Medical University, Nanjing 211166, China

${ }^{8}$ Department of Urology, Sir Run Run Hospital, Nanjing Medical University, 109 Longmian Road, Jiangning, Nanjing 211100, Jiangsu, China

${ }^{9}$ China Exposomics Institute (CEI) Precision Medicine Co. Ltd,

Shanghai 200120, China

Full list of author information is available at the end of the article
Excessive accumulation of environment pollutants in tissues and organs tends to cause damage to the human body, eventually leading to the various diseases. Due to global climate change, pesticides abuse and industry development, individuals are frequently exposed to pollutants from mining and smelting metal ores, pesticide manufacturing and application, wood preservatives, even drinking and food intake $[1,2]$. There are three common environmentally-derived pollutants that require special attention, which are organophosphorus pesticide residues, dimethoate [3], from pesticide abuse, polycyclic aromatic hydrocarbons(PAHs), benzo(a)pyrene (BaP) [4], 
from air pollution, and bisphenol A(BPA) [5] from the plastics industry.

Dimethoate, an organophosphorus insecticide, is widely used for controlling a wide range of insects. However, many studies have shown adverse effects on mammalian [6-8]. Several studies have documented that the carcinogenicity [9] and developmental toxicity $[10,11]$ of dimethoate which can lead to a reduction in plasma cholinesterase [12] . Likewise, $\mathrm{BaP}$ has been characterized as a stronger carcinogen than other PAHs compounds [13] which can cause DNA damage and plays a role in lung carcinogenesis [14], atherosclerosis [15] and so on [1618]. BPA is an endocrine disruptor chemical which can induce carcinogenesis, reproductive toxicity, abnormal immune response, and developmental disorders of brain and nervous system through various signaling pathways [19] .

More recently, there has been growing recognition of the vital links between pollutants accumulation and health. Different approaches for these pollutants removal from the environment including biodegradation and non-biodegradation have been developed so far [20] . Well-known methods include degradation (chemical or microbial) or adsorption on different types of materials [21] . However, the elimination of the pollutants that have already been abnormally accumulated in human body has not been reported.

It has been reported that physical exercise is an efficient non-pharmacological intervention for human health [22, 23]. Exercise has also been shown to be beneficial in the treatment of many chronic diseases through changing the metabolism state, strengthening muscle, and improving immunity [24] . Physical exercise is considered a part of healthy life style. The individuals who exercise regularly can expect positive feedback from their environment and social contact, and even can be beneficial for the treatment of psychiatric diseases [25]. Marisa Toups [26] evaluated the effect of exercise for depression patients during 12 weeks of exercise augmentation and found positive valence symptoms improvement with exercise treatment for depression, and this change correlates well with overall outcome. Likewise, the improvement of metabolic diseases like obesity, hyperlipidemia, metabolic syndrome, polycystic ovarian syndrome, type 2 diabetes, type 1 diabetes by exercise had also been reported [27] . In a clinical study, post-dinner moderate-intensity exercise of those patients with type 2 diabetes could reduce the 2-hour postprandial glucose spike, mean glucose level, and peak glucose level compared to the control condition [28].Moreover, regular physical exercises could induce antiatherogenic adaptations in vascular function and structure, improve myocardial regeneration capacity and cardiac parasympathetic regulation [29] . Besides, physical exercises can also improve lung function [30] and the quality of life in patients with malignant tumor [31] . Exercise could also reduce the likelihood of air pollutionrelated mortality [32,33]. The extent, however, to which elimination of environment pollutants may be attributed to physical exercises is still poorly understood.

Here, we recruited 200 individuals to receive a physical exercise for a period of 3 months in order to assess the correlation between the improvement effect of pollutants and different physical exercises. What's more, identification of the most significant factors which can influence the improvement of physical exercise intervention may provide new insights into pollutants elimination in young people.

\section{Materials \& methods}

Study design and participants

All procedures including sampling and examination were performed in agreement with the principles set in the Declaration of Helsinki and its later amendments (2013). All participants were informed about the objectives of the study and experimental procedures and signed the informed consent form. A total of 200 freshmen of the Hohai University (Nanjing, Jiangsu province, China) were analyzed, in which there were 100 males and 100 females aged from 17 to 19 . The height, weight, BMI, and changes in urine pollutants (dimethoate, bisphenol A, Benzo(a) pyrene) of each participant before and after the exercise program were recorded.

\section{Inclusion and exclusion criteria}

Inclusion criteria: a) Top 100 male and female with higher pollutants level [34]; b) Aged from 17 to 19; c) Did not engage in any regular exercise activities for 2 months prior to enrollment in the study (Regular exercise was defined as exercising more than once a week.).

Exclusion criteria: a) Unable to participate in the exercise due to physical disability; b) Severe heart, lung, liver, or renal disorders; c) Participating in other exercise after choosing the exercise according to preference;

\section{Exercise program}

The exercise program lasted 3 months, 3 times a week, $90 \mathrm{~min}$ every time, the subjects were not allowed to participate in any other exercises after they chose their preference exercise in their leisure Duration. Exercise items include basketball, volleyball, ping pong, handball, tennis, football, badminton, Latin dance, rhythmic gymnastics, bodybuilding, yoga, and shaping. Subjects from Hohai University underwent $90 \mathrm{~min}$ sessions. The heart rate (HR) before and after exercise was monitored. The first 
30 min of exercise were a warm-up period, where speed was progressively increased and aerobic exercise with moderate severity equal to $60-70 \%$ of the maximum HR. Peak heart rate will be recorded immediately upon the end of the exercise. Thereafter, $10 \mathrm{~min}$ of cooling down consisted of stretching movements of muscles in lower extremities and 1-min relaxation of the whole body.

\section{Sample collection}

Collection of morning urine samples (second portion) was performed using plastic Vacuette ${ }^{\circledR}$ Urine Collection Cups (Greiner Bio-One International AG, Austria). Only healthy subjects without chronic diseases were involved in the current investigation in order to avoid side effects and interactions of diseases on the studied parameters.

\section{Sample processing}

Samples were collected at predetermined time intervals and filtered through a membrane filter of $0.22 \mu \mathrm{m}$. The $\mathrm{pH}$ of respective mixtures was adjusted to 5.4 by adding acetic acid-sodium acetate buffer $(0.5 \mathrm{M})$, then $\beta$-glucuronidase/arylsulfase $(10 \mu \mathrm{L})$, and vitamin C $(5 \mathrm{mg})$ were added and incubated overnight at room temperature to complete the enzymatic hydrolysis. The samples after enzymatic hydrolysis were extracted by solid-phase extraction with an SPE column (C18 ENVIJI $0.25 \mathrm{~g}$ ). The extract was eluted with methanol $(2 \mathrm{~mL})$ and dried with nitrogen. Finally, methanol $(100 \mu \mathrm{L})$ was re-dissolved as the analyte to be determined. $50 \mu \mathrm{L}$ of the analyte to be tested was transferred to a liquid chromatography bottle with a microsyringe, which was specially used for the injection analysis of $\mathrm{BaP}$. Evaluation of dimethoate, $\mathrm{BPA}$, and BaP levels in the urine of examinees was performed using Liquid chromatography-mass spectrometry (LC-MS). The $1 \mu \mathrm{g} / \mathrm{ml}$ standard working solutions of dimethoate, BPA, and $\mathrm{BaP}$ were prepared with methanol as solvent. After continuous dilution of 104 times, it became the standard working solution of $100 \mathrm{pg} / \mathrm{ml}$. Take $\mathrm{BaP}$ as an example, different concentrations of $\mathrm{BaP}$ standard working solution were prepared. $50 \mu \mathrm{L}$ of each $\mathrm{BaP}$ standard working solution was transferred to a liquid chromatography bottle with a microsyringe, which was specially used for the injection analysis of BaP standard samples.

\section{Statistical analysis}

The data were expressed as the frequencies (n), percentages (\%), means \pm standard deviations (SDs), median (inter-quartile range), and were analyzed with $\mathrm{R}$ version 4.0.2. Count data were analyzed with the chi-square test. If measurement data conformed to a normal distribution, the t-test was used to analyze. The Mann-Whitney U-test was used for comparing unorthodox distribution data. Before regression analysis, the factors are verified by multiple linear regression to verify independence. The difference value before and after exercise was calculated and categorized into three grades. The possible effects of the determinants on three pollutants were analyzed through multivariate logistic regression analysis. A difference with $P<0.05$ was considered statistically significant.

\section{Results}

\section{Characteristics of individuals}

A total of 200 individuals were enrolled in the present study (Table 1), including 100 female and 100 male individuals. Participants can choose preference exercise activities depending on their own interests. Ultimately, 12 kinds of sports were included in the final cohort (basketball, volleyball, ping pong, handball, tennis, football, badminton, Latin dance, rhythmic gymnastics, bodybuilding, yoga and shaping).

\section{Levels of three environmental pollutants were reduced after physical exercises}

The level of dimethoate, BaP and BPA of 200 individuals were measured before and after 3 months physical exercises by a high-performance liquid chromatography tandem mass spectrometry-based method. Totally, the level of dimethoate, $\mathrm{BaP}$ and BPA $(8.06 \pm 1.51 \mathrm{ng} /$ $\mathrm{mL}, 0.32 \pm 0.08 \mathrm{pg} / \mathrm{mL}, 3.19 \pm 0.54 \mathrm{ng} / \mathrm{mL}$ ) were lower than that $(10.78 \pm 1.37 \mathrm{ng} / \mathrm{mL}, \quad 0.4 \pm 0.05 \mathrm{pg} / \mathrm{mL}$, $4.07 \pm 0.38 \mathrm{ng} / \mathrm{mL}$ ) after physical exercises, respectively, of which the differences were statistically significant (Table 2). Besides, effects of gender on pollutants elimination were analyzed. There is no statistical difference on the elimination of dimethoate between male and female (Fig. 1a) The elimination of $\mathrm{BaP}$ in female was higher than that in male (Fig. 1b). However, the elimination on BPA in male was higher than that in female (Fig. 1c).

\section{The effect of gender preference physical exercises on the elimination of pollutants}

Due to the gender difference, men and women have preferences when choosing physical exercise. In order to perform statistical analysis, we selected those physical exercises with subjects more than 8 to analyze among the 12 sports. Although there was no statistical difference on the improvement effect between football and other male preference exercises, basketball showed the best elimination potential (Fig. 2a, c) and football showed the worst elimination potential on dimethoate and BPA. Nevertheless, football revealed the best elimination potential on BaP (Fig. 2b). All male preference physical exercises showed the best elimination potential on dimethoate but the worst on $\mathrm{BaP}$ (Fig. 2d). Interestingly, all 5 female preference physical exercises showed the same tendency of 
Table 1 Characteristics of individuals

\begin{tabular}{|c|c|c|c|c|c|c|c|c|}
\hline Values & Male(n\%) & & Female(n\%) & & Total(n\%) & & Statistic $\left(t / x^{2}\right)$ & P-Value \\
\hline $\mathbf{n}$ & 100 & & 100 & & & & & \\
\hline Height(cm) & $174.98 \pm 5.49$ & & $162.27 \pm 4.49$ & & $168.62 \pm 8.10$ & & & \\
\hline weight (kg) & $65.6 \pm 6.06$ & & $54.66 \pm 4.89$ & & $60.13 \pm 7.76$ & & & \\
\hline Waistline(cm) & $76.71 \pm 5.08$ & & $69.85 \pm 4.63$ & & $73.28 \pm 5.94$ & & & \\
\hline BMI $\left(\mathrm{kg} / \mathrm{m}^{2}\right)$ & $21.41 \pm 1.46$ & & $20.74 \pm 1.36$ & & $21.07 \pm 1.45$ & & & \\
\hline \multicolumn{9}{|l|}{ Sport type } \\
\hline Basketball & 17 & $10.00 \%$ & 0 & $0.00 \%$ & 17 & $17.00 \%$ & & \\
\hline Volleyball & 0 & $0.00 \%$ & 16 & $14.00 \%$ & 16 & $16.00 \%$ & & \\
\hline Ping pong & 9 & $9.00 \%$ & 32 & $32.00 \%$ & 41 & $41.00 \%$ & & \\
\hline Handball & 0 & $0.00 \%$ & 12 & $12.00 \%$ & 12 & $12.00 \%$ & & \\
\hline Tennis & 22 & $22.00 \%$ & 0 & $0.00 \%$ & 22 & $22.00 \%$ & & \\
\hline Football & 18 & $18.00 \%$ & 0 & $0.00 \%$ & 18 & $18.00 \%$ & & \\
\hline Badminton & 24 & $24.00 \%$ & 13 & $13.00 \%$ & 37 & $37.00 \%$ & & \\
\hline Latin dance & 0 & $0.00 \%$ & 3 & $3.00 \%$ & 3 & $3.00 \%$ & & \\
\hline Rhythmic gymnastics & 0 & $0.00 \%$ & 5 & $5.00 \%$ & 5 & $5.00 \%$ & & \\
\hline Bodybuilding & 10 & $10.00 \%$ & 0 & $0.00 \%$ & 10 & $10.00 \%$ & & \\
\hline Yoga & 0 & $0.00 \%$ & 6 & $4.00 \%$ & 6 & $6.00 \%$ & & \\
\hline Shaping & 0 & $0.00 \%$ & 13 & $13.00 \%$ & 13 & $13.00 \%$ & & \\
\hline RHR & $82.50 \pm 10.76$ & & $81.86 \pm 10.32$ & & $82.18 \pm 10.52$ & & 0.429 & 0.640 \\
\hline PHR & $130.63 \pm 22.69$ & & $131.46 \pm 21.67$ & & $131.05 \pm 22.14$ & & 0.729 & 0.830 \\
\hline HR(D-value) & $48.13 \pm 20.18$ & & $49.60 \pm 20.36$ & & $48.87 \pm 20.23$ & & 0.609 & 1.470 \\
\hline
\end{tabular}

Note: Statistical methods: Independent sample T test, chi-square test. RHR:resting heart rate; PHR:postexercise heart rate; HR(D-value) $=$ PHR-RHR

Table 2 Comparation of the level of three pollutants before and after exercise

\begin{tabular}{|c|c|c|c|c|c|c|c|c|}
\hline \multirow[t]{2}{*}{ Values } & \multicolumn{3}{|c|}{ Before-exercises } & \multicolumn{3}{|c|}{ After-exercises } & \multirow[t]{2}{*}{ Statistic(t) } & \multirow[t]{2}{*}{ P-Value } \\
\hline & Male (100) & Female (100) & Total & Male (100) & Female (100) & Total & & \\
\hline Dimethoate $(\mathrm{ng} / \mathrm{mL})$ & $11.82 \pm 1.05$ & $9.74 \pm 0.68$ & $10.78 \pm 1.37$ & $8.79 \pm 1.45$ & $7.34 \pm 1.18$ & $8.06 \pm 1.51$ & 42.101 & $0.000^{\#}$ \\
\hline $\mathrm{BaP}(\mathrm{pg} / \mathrm{mL})$ & $0.44 \pm 0.04$ & $0.36 \pm 0.03$ & $0.4 \pm 0.05$ & $0.38 \pm 0.06$ & $0.27 \pm 0.04$ & $0.32 \pm 0.08$ & 29.084 & $0.000^{\#}$ \\
\hline BPA (ng/mL) & $4.03+0.34$ & $4.12 \pm 0.39$ & $4.07 \pm 0.38$ & $3.10+0.51$ & $3.28 \pm 0.55$ & $3.19 \pm 0.54$ & 35.228 & $0.000^{\#}$ \\
\hline
\end{tabular}

Note: Statistical methods: Paired Sample T test;

\# : Comparation between total before-exercises of pollutants level and after-exercises of pollutants level. $0.000: P<0.0001$

elimination potential on three pollutants but there was no statistical difference (Fig. 2e-g) Conversely, all female preference physical exercises showed the best elimination potential on BaP (Fig. 2h). And in co preference exercises, the same elimination potential was observed which showed the best elimination potential on BaP (Fig. 2j) but no difference was observed on dimethoate and BPA (Fig. 2i,k). Male preference physical exercises, female preference physical exercises and co preference physical exercises were defined according to gender preference (Fig. 2l).Furthermore,we splitted the 12 sports into indoor (Ping pong, handball, badminton, Latin dance, rhythmic gymnastics, bodybuilding, yoga and shaping) and outdoor exercises (Basketball, volleyball,tennis, football) and investigated the elimination potential between genders on the three pollutants. The results showed no statistical difference on the improvement effect between male and female on dimethoate and BPA (Fig. 2m,n) but female seemed to have a better pollutant level reduction on Bap in both indoor and outdoor exercises (Fig. 20).

\section{Linear correlation verification of difference factors}

The difference factors were verified by linear correlation: in male and female participants, there was no significant correlation among the difference values of height, weight, waistline, dimethoate, BaP, BPA and HR. There was a high 

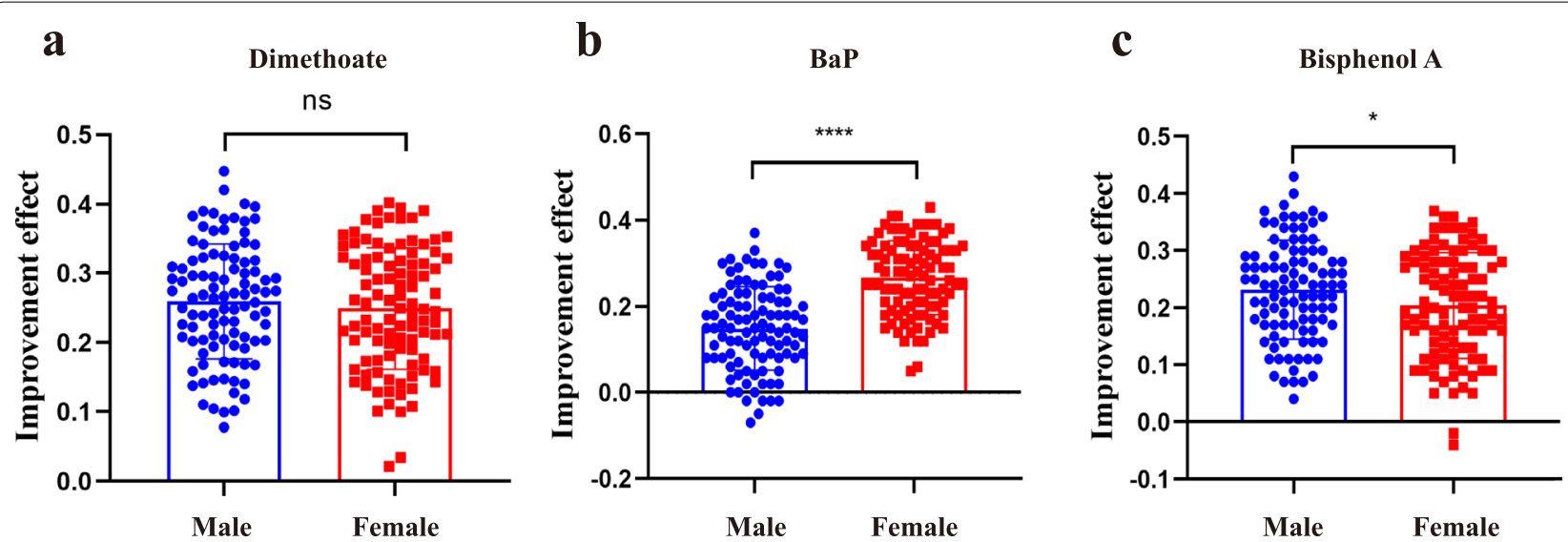

Fig. 1 Comparation of the elimination of three pollutants between male and female. a:The improvement effect on dimethoate between male \&female; $\mathbf{b}$ The improvement effect on BaP between male \&female; $\mathbf{c}$ The improvement effect on BPA between male \&female). Note: Improvement effect $=($ post-intervention level minus pre-intervention level)/post-intervention level

correlation between BMI and the level of dimethoate, $\mathrm{BaP}$ and BPA after exercise-intervention. BMI was highly correlated with height , weight , waistline, however, sport type and HR were not significantly associated with the rest indicator (Fig. 3).

\section{Multivariate ordered logistic and logistic regression analysis}

Table 3 presents the predictive factors towards the different outcomes of interest using multivariate ordered logistic and logistic regression analysis. The results showed that the degree of HR change was the risk factor influencing the elimination of dimethoate, $\mathrm{BaP}$ and $\mathrm{BPA}$, and the influence degree of the three pollutants was equal. BMI was a protective factor influencing the elimination of dimethoate, $\mathrm{BaP}$ and BPA. Those who are with lower $\mathrm{BMI}$, the elimination of the pollutants was more obvious, and the difference was statistically significant. Gender also affects the elimination of these pollutants. But the type of physical exercise had no significant effect on the three pollutants elimination.

\section{Discussion}

Excessive accumulation of pollutants in human body could lead to the morbidity of various diseases. However, the possible harms of these pollutants are tended to be ignored [35]. Moreover, because of abnormal concentrations of pollutants on health, it is urgent to find ways to reduce the pollutants levels in the human body. Current approaches to remove common environment pollutants are based on the membrane technology for drinking water and reducing the source of production. Nevertheless, how to eliminate the pollutants that had already been accumulated in the human body is still underexplored and underreported. The notion, "Exercise as medicine", has been termed as exercise and physical activity are increasingly becoming key tools in the treatment and prevention of several medical conditions including arthritis and diabetes [36] and more importantly physical exercise could serve as a tool to help the immune system against COVID-19 [37] . The beneficial adaptive responses to regular physical exercise are appreciated and include improvements in metabolism, redox state, and inflammation scenario in several tissue [38]. Moreover, several studies had indicated that regulate physical exercises could reduce the air pollution-related mortality and suggested that aerobic exercise training protects against air pollution and environmental tobacco smoke-induced lung inflammation [32, 33, 39, 40]. But to our knowledge, this is the first report about elimination of pollutants by physical exercises Therefore, we aim to determine if physical exercises had a positive effect on the elimination of various pollutants.

(See figure on next page.)

Fig. 2 Elimination potential of different physical exercises on three pollutants. (a-d: Elimination potential of different physical exercises on three pollutants in male preference physical exercises; $\mathbf{e}-\mathbf{h}$ : Elimination potential of different physical exercises on three pollutants in female preference physical exercises; $\mathbf{i}$-k: Elimination potential of different physical exercises on three pollutants in co preference physical exercises; $\mathbf{l}$ : Definition of male preference physical exercises, female preference physical exercises and co preference physical exercises; $\mathbf{m}$-o:Elimination potential of indoor and outdoor physical exercises on three pollutants) 


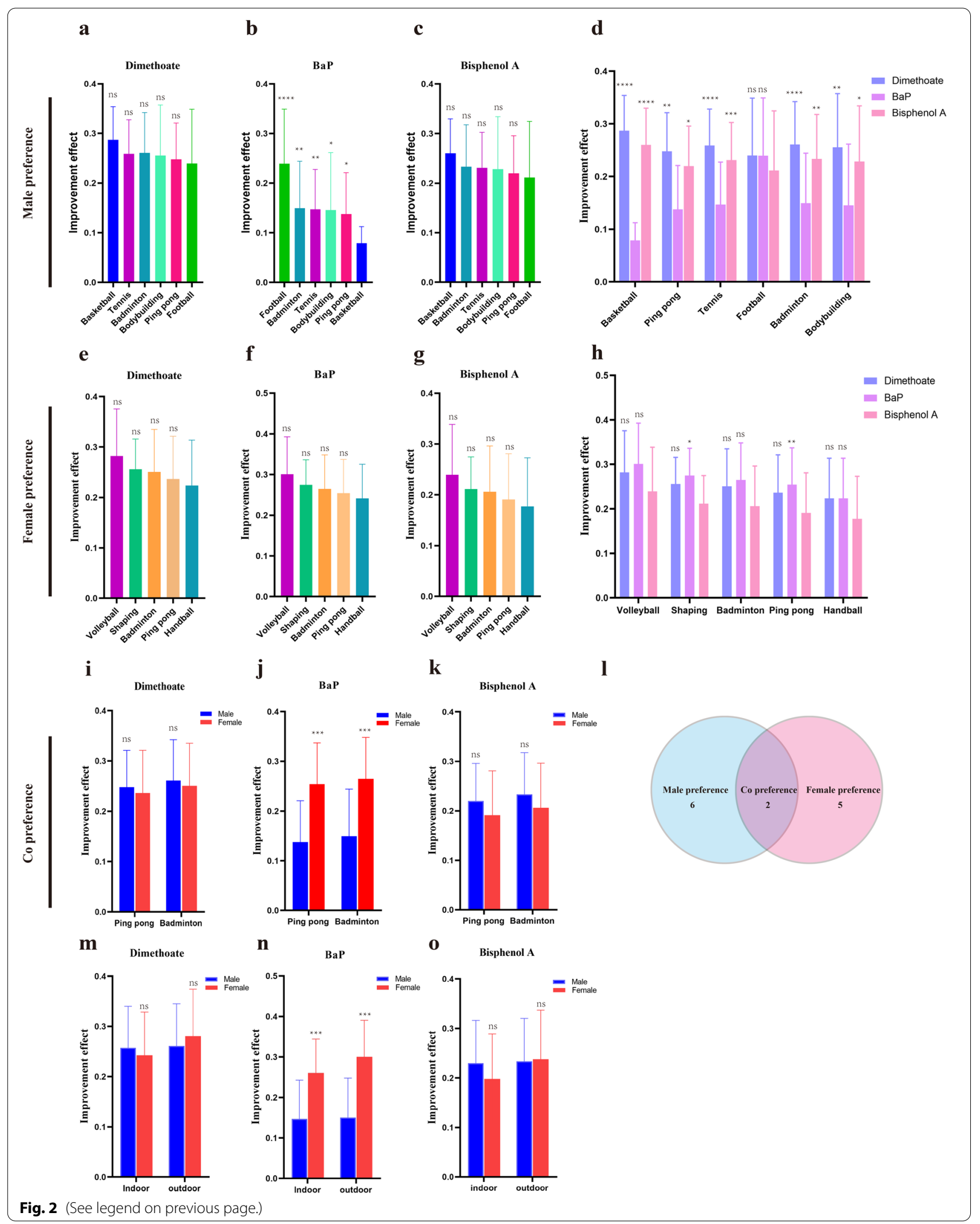




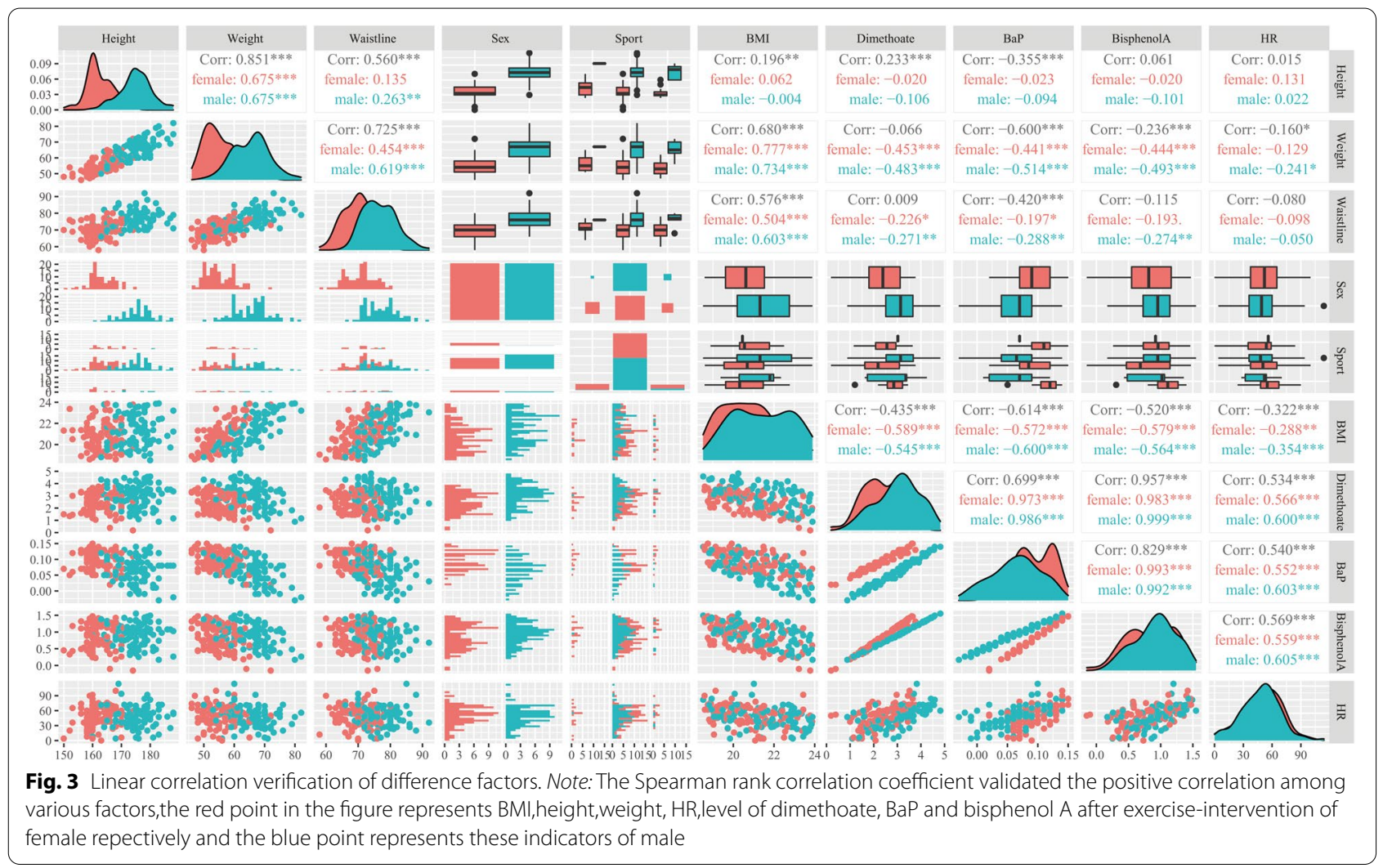

Table 3 Multivariate ordered logistic and logistic regression analysis

\begin{tabular}{|c|c|c|c|c|c|c|c|c|}
\hline \multirow{2}{*}{$\begin{array}{l}\text { Factors } \\
\text { Dimethoate }\end{array}$} & \multirow[b]{2}{*}{ HR(D-value) } & \multirow{2}{*}{$\begin{array}{l}\boldsymbol{\beta} \\
0.063\end{array}$} & \multirow{2}{*}{$\begin{array}{l}\text { S.E } \\
0.009\end{array}$} & \multirow{2}{*}{$\begin{array}{l}\text { Wald } \\
50.765\end{array}$} & \multirow{2}{*}{$\begin{array}{l}\text { P-Value } \\
0.000\end{array}$} & \multirow{2}{*}{$\begin{array}{l}\text { OR } \\
1.065\end{array}$} & \multicolumn{2}{|c|}{$\begin{array}{l}\text { 95\%Cl (lower- } \\
\text { uper) }\end{array}$} \\
\hline & & & & & & & 1.046 & 1.083 \\
\hline & BMI & -0.585 & 0.109 & 28.669 & 0.000 & 0.557 & 0.450 & 0.690 \\
\hline & Sex & 1.211 & 0.307 & 15.564 & 0.000 & 3.356 & 1.839 & 6.124 \\
\hline & Sport type & 0.459 & 0.440 & 1.090 & 0.296 & 1.583 & 0.668 & 3.750 \\
\hline \multirow[t]{4}{*}{ BaP } & HR(D-value) & 0.069 & 0.009 & 55.957 & 0.000 & 1.071 & 1.052 & 1.091 \\
\hline & BMI & -0.729 & 0.115 & 40.378 & 0.000 & 0.482 & 0.385 & 0.604 \\
\hline & Sex & 0.947 & 0.307 & 9.488 & 0.002 & 2.578 & 1.411 & 4.708 \\
\hline & Sport type & 0.258 & 0.445 & 0.336 & 0.562 & 1.294 & 0.541 & 3.093 \\
\hline \multirow[t]{4}{*}{ BPA } & HR(D-value) & 0.060 & 0.009 & 45.206 & 0.000 & 1.061 & 1.043 & 1.080 \\
\hline & $\mathrm{BMI}$ & -0.882 & 0.126 & 49.306 & 0.000 & 0.414 & 0.323 & 0.529 \\
\hline & Sex & -2.487 & 0.348 & 51.134 & 0.000 & 0.083 & 0.042 & 0.164 \\
\hline & Sport type & 0.479 & 0.458 & 1.093 & 0.296 & 1.614 & 0.658 & 3.963 \\
\hline
\end{tabular}

Note: The Sex variable was assigned to male

Our previous study showed that the average level of environmental pollutants accumulation in young people is relatively high and differs in the youth who live in different regions [34]. The young individuals seem to have relatively irregular diets and lifestyles which could increase the risk of pollutants accumulation. Herein, we reported that the levels of dimethoate, $\mathrm{BaP}$ and $\mathrm{BPA}$ were significantly reduced after 3 months' physical exercises in young people.

The result revealed that exercise could serve as an efficient way to eliminate the pollutants level in the young people. Besides, the elimination potential appears to differ by sex. The elimination potential on 
BPA in male was higher than that in female; Inversely, the elimination potential on $\mathrm{BaP}$ in female was higher than that in male. Interestingly, the level of dimethoate and $\mathrm{BaP}$ in male was significantly higher than that in female before exercise which may suggested that different lifestyle like smoking and eating barbecued food could contribute to the accumulation of $\mathrm{BaP}[41,42]$.

Different exercises seem to have various elimination potential on environmental pollutants in the present study. Take the male preference physical exercises as an example, basketball showed the best elimination potential on dimethoate and BPA, although there was no statistical difference on the elimination potential among all male preference physical exercises. This provides a very good reference for male when choosing exercises. But due to insufficient samples size of each physical exercise,no statistically significant difference was obtained among the elimination potential of different male preference physical exercises and female preference physical exercises on dimethoate and BPA. One unexpected result was that all male preference physical exercises showed the worst elimination potential on $\mathrm{BaP}$ among three pollutants, however, the results in female preference physical exercises were opposite. The same results were observed in indoor exercise and outdoor exercises. It is reported that $\mathrm{BaP}$, one of the common PAHs, has been known as a kind of xenoestrogen, whose pollutants possess estrogenic and/or antiestrogenic activities [43]. This may contribute to the difference in the elimination potential on $\mathrm{BaP}$ between men and women and may also indicate that the metabolism of $\mathrm{BaP}$ is dependent on estrogen but the exact mechanism remains to be explored.

Since the lipophilicity of most persistent organic pollutants (POPs), it has been widely studied that POPs could be stored in the adipose tissue. Herein, we found that BMI had a high correlation with the elimination potential on dimethoate, $\mathrm{BaP}$ and BPA after exercise-intervention. In addition, multivariate ordered logistic revealed that those who are with lower BMI tended to have better elimination of pollutants. This rather interesting finding might be explained by the fact that some obese individuals with metabolic disorder may experience the abnormal metabolism of pollutants $[44,45]$ which means that a normal BMI is required for a better elimination of pollutants. Besides of the index of BMI, we also found that HR change was a risk factor influencing the elimination of dimethoate, $\mathrm{BaP}$ and BPA. It was well documented that alteration of HR could reveal the intensity of exercise [46]. This indicated that a certain intensity of exercise is needed to achieve a better elimination of pollutants.

Taken together, these findings suggest that physical exercise is a novel and efficacious approach for reducing pollutants level in young people and could contribute to our understanding of the health benefits of physical exercises and could partially provide a reference on promoting the young individuals to actively participate in physical exercises which have the best elimination potential on pollutants, thus develop the habit of regular physical exercise, and improve self-health ability and physical health level. But due to insufficient samples size of each physical exercise,we did not obtain a satifying results that the elimination potential of different physical exercises on the three pollutants. Therefore, it is necessary to further expand the sample size in the follow-up studies due to the small sample size and the absence of longterm follow-up studies included in this study.

\section{Conclusion}

The present findings indicate that physical exercises can be considered as a novel approach to eliminate pollutants level in human body and can also give suggestions for choosing specific physical exercises to male and female individuals. Moreover, those who are with higher BMI need to lose weight before eliminating pollutant level through physical exercises.

\section{Abbreviations \\ BaP: Benzo(a)pyrene; BPA: Bisphenol A; BMI: Body mass index; PAHs: Polycyclic aromatic hydrocarbons; LC-MS: Liquid chromatography-mass spectrometry; DNA: Deoxyribonucleic acid; HR: Heart rate; RHR: resting heart rate; PHR: Postexercise heart rate; POPs: Persistent organic pollutants. \\ Acknowledgements \\ We would like to thank: Teachers of Hohai university who collect data and urine samples. \\ China Exposomics Institute (CEI) Precision Medicine Co. Ltd. for testing the urine sample. \\ Core Laboratory, Sir Run Run Hospital, Nanjing Medical University for provid- ing the experimental platform and data analysis.}

\section{Authors' contributions}

YJX, JW, NS, and BX contributed equally to the design of the study and the direction of its implementation, including supervision of the field activities, quality assurance, and control. FZ and XLX supervised the field activities. YJX, NWZ, and JY were responsible for sample collection. YJX, HLG, HL, NS, and BX helped conduct the literature review and prepare the Materials and methods and the Discussion sections of the text. ZXD, FRZ, AQW, BM, YJD, and NS

designed the study's analytic strategy and conducted the data analysis. All authors read and approved the final manuscript.

\section{Funding}

This work was supported by the Chinese National Science Foundation (32071145, 31771572), the Nature Science Foundation of Jiangsu Province (BK20191356), the Six talent peaks project in Jiangsu Province (yy-014), Qin Lan Project of Jiangsu Province (KY520R202025), the Science and Technology Development Fund of Nanjing Medical University - General Project (NMUB2019079), the Natural Science Foundation of the Jiangsu Higher Education Institutions of China (20KJB180004), the Chinese National Science Foundation (81700710), the joint project of Sir Run Run Hospital, Nanjing Medical University and China Exposomics Institute (CEI) Precision Medicine 
Co. Ltd. (YFHX2020-001) and the joint project of Hohai University and China Exposomics Institute (CEI) Precision Medicine Co. Ltd. (1094/CZ819129916).

\section{Availability of data and materials}

All data generated or analyzed during this study are included in this published article

\section{Declarations}

\section{Ethics approval and consent to participate}

All procedures, including sampling and examination, were performed in agreement with the principles set forth in the Declaration of Helsinki and its later amendments (2013). All examinees were invited to participate and voluntarily took part in the present study. All subjects were informed about the objectives of the study and experimental procedures and signed the informed consent form. The study protocol was reviewed and approved by the Ethical Review Committee of Sir Run Run Hospital, Nanjing Medical University (2019-SR-018).

\section{Consent for publication}

Not applicable.

\section{Competing interests}

The authors declare that they have no competing interests.

\section{Author details}

${ }^{1}$ Hohai University, Nanjing 210098, China. ${ }^{2}$ Core Laboratory, Sir Run Run Hospital, Nanjing Medical University, Nanjing 211166, China. ${ }^{3}$ Department of Infectious Diseases, Taizhou People's Hospital, Taizhou 225300, China. ${ }^{4}$ General surgery department, Sir Run Run Hospital, Nanjing Medical University, Nanjing 211166, China. ${ }^{5}$ Medical School of Nanjing University, Nanjing 210093, China. ${ }^{6}$ Affiliated Hospital of Integrated Traditional Chinese and Western Medicine, Nanjing University of Chinese Medicine, Nanjing 210028, China. ${ }^{7}$ Affiliated Hospital of Nanjing University of Chinese Medicine, Nanjing 210029, China. ${ }^{8}$ Department of Urology, Sir Run Run Hospital, Nanjing Medical University, 109 Longmian Road, Jiangning, Nanjing 211100, Jiangsu, China. ${ }^{9}$ China Exposomics Institute (CEI) Precision Medicine Co. Ltd, Shanghai 200120, China.

\section{Received: 12 August 2021 Accepted: 21 January 2022}

Published online: 03 February 2022

\section{References}

1. Domingo JL, Nadal M. Human exposure to per- and polyfluoroalkyl substances (PFAS) through drinking water: a review of the recent scientific literature. Environ Res. 2019;177:108648.

2. Gonzalez-Casanova I, Stein AD, Barraza-Villarreal A, Feregrino RG, DiGirolamo A, Hernandez-Cadena L, et al. Prenatal exposure to environmental pollutants and child development trajectories through 7 years. Int J Hyg Environ Health. 2018;221(4):616-22.

3. Meftaul IM, Venkateswarlu K, Dharmarajan R, Annamalai P, Megharaj M. Sorption-desorption of dimethoate in urban soils and potential environmental impacts. Environ Sci Process Impacts. 2020;22(11):2256-65.

4. Miller KP, Ramos KS. Impact of cellular metabolism on the biological effects of benzo[a]pyrene and related hydrocarbons. Drug Metab Rev. 2001;33(1):1-35.

5. Michalowicz J. Bisphenol A--sources, toxicity and biotransformation. Environ Toxicol Pharmacol. 2014:37(2):738-58.

6. Jallouli M, Dhouib lel B, Dhouib H, Gharbi N, El Fazaa S. Effects of dimethoate in male mice reproductive parameters. Regul Toxicol Pharmacol. 2015;73(3):853-8.

7. Martinez-Morcillo S, Perez-Lopez M, Soler-Rodriguez F, Gonzalez A. The organophosphorus pesticide dimethoate decreases cell viability and induces changes in different biochemical parameters of rat pancreatic stellate cells. Toxicol in Vitro. 2019;54:89-97.

8. Sayim F. Histopathological effects of dimethoate on testes of rats. Bull Environ Contam Toxicol. 2007;78(6):479-84.
9. Pardo LA, Beane Freeman LE, Lerro CC, Andreotti G, Hofmann JN, Parks $C G$, et al. Pesticide exposure and risk of aggressive prostate cancer among private pesticide applicators. Environ Health. 2020;19(1):30.

10. Scalisi EM, Pecoraro R, Salvaggio A, Corsaro A, Messina G, Ignoto S, et al. Evaluation of dimethoate toxicity on fertilization and on embryonic development of Paracentrotus lividus (Lamarck, 1816). Toxicol Res (Camb). 2020;9(4):537-43.

11. Verma R, Mohanty B. Early-life exposure to dimethoate-induced reproductive toxicity: evaluation of effects on pituitary-testicular axis of mice. Toxicol Sci. 2009;112(2):450-8.

12. Van Scoy A, Pennell A, Zhang X. Environmental fate and toxicology of Dimethoate. Rev Environ Contam Toxicol. 2016;237:53-70.

13. Devanesan PD, Cremonesi P, Nunnally JE, Rogan EG, Cavalieri EL. Metabolism and mutagenicity of dibenzo[a,e]pyrene and the very potent environmental carcinogen dibenzo[a,I]pyrene. Chem Res Toxicol. 1990;3(6):580-6.

14. Shi Q, Godschalk RWL, van Schooten FJ. Inflammation and the chemical carcinogen benzo[a]pyrene: partners in crime. Mutat Res. 2017;774:12-24.

15. Kress JM, Dio LD, Heck L, Pulliero A, Izzotti A, Laarmann K, et al. Human primary endothelial cells are impaired in nucleotide excision repair and sensitive to benzo[a]pyrene compared with smooth muscle cells and pericytes. Sci Rep. 2019;9(1):13800.

16. Bucher S, Tete A, Podechard N, Liamin M, Le Guillou D, Chevanne M, et al. Co-exposure to benzo[a]pyrene and ethanol induces a pathological progression of liver steatosis in vitro and in vivo. Sci Rep. 2018;8(1):5963.

17. Defois C, Ratel J, Denis S, Batut B, Beugnot R, Peyretaillade E, et al. Environmental pollutant Benzo[a]Pyrene impacts the volatile Metabolome and Transcriptome of the human gut microbiota. Front Microbiol. 2017:8:1562.

18. Hazra A, Grossman HB, Zhu Y, Luo S, Spitz MR, Wu X. Benzo[a]pyrene diol epoxide-induced 9p21 aberrations associated with genetic predisposition to bladder cancer. Genes Chromosomes Cancer. 2004;41(4):330-8.

19. Murata M, Kang JH. Bisphenol a (BPA) and cell signaling pathways. Biotechnol Adv. 2018:36(1):311-27.

20. Bilal M, lqbal HMN, Barcelo D. Persistence of pesticides-based contaminants in the environment and their effective degradation using laccaseassisted biocatalytic systems. Sci Total Environ. 2019;695:133896.

21. Mitrovic T, Lazovic S, Nastasijevic B, Pasti IA, Vasic V, Lazarevic-Pasti T. Nonthermal plasma needle as an effective tool in dimethoate removal from water. J Environ Manag. 2019;246:63-70.

22. Ambrose KR, Golightly YM. Physical exercise as non-pharmacological treatment of chronic pain: why and when. Best Pract Res Clin Rheumatol. 2015;29(1):120-30.

23. Fu Q, Levine BD. Exercise and non-pharmacological treatment of POTS. Auton Neurosci. 2018;215:20-7.

24. Garber CE, Blissmer B, Deschenes MR, Franklin BA, Lamonte MJ, Lee IM, et al. American College of Sports M: American College of Sports Medicine position stand. Quantity and quality of exercise for developing and maintaining cardiorespiratory, musculoskeletal, and neuromotor fitness in apparently healthy adults: guidance for prescribing exercise. Med Sci Sports Exerc. 2011;43(7):1334-59.

25. Schuch FB, Stubbs B. The role of exercise in preventing and treating depression. Curr Sports Med Rep. 2019;18(8):299-304.

26. Toups M, Carmody T, Greer T, Rethorst C, Grannemann B, Trivedi MH. Exercise is an effective treatment for positive valence symptoms in major depression. J Affect Disord. 2017;209:188-94.

27. Colberg SR, Albright AL, Blissmer BJ, Braun B, Chasan-Taber L, Fernhall B, et al. American College of Sports $M$ et al: exercise and type 2 diabetes: American College of Sports Medicine and the American Diabetes Association: joint position statement. Exercise and type 2 diabetes. Med Sci Sports Exerc. 2010;42(12):2282-303.

28. Li Z, Hu Y, Yan R, Li H, Zhang D, Li F, et al. Twenty minute moderate-intensity post-dinner exercise reduces the postprandial glucose response in Chinese patients with type 2 diabetes. Med Sci Monit. 2018;24:7170-7.

29. Schuttler D, Clauss S, Weckbach LT, Brunner S: Molecular Mechanisms of Cardiac Remodeling and Regeneration in Physical Exercise. Cells 2019, $8(10)$.

30. Armstrong $\mathrm{M}$, Vogiatzis I. Personalized exercise training in chronic lung diseases. Respirology. 2019;24(9):854-62. 
31. Dieli-Conwright CM, Courneya KS, Demark-Wahnefried W, Sami N, Lee K, Sweeney FC, et al. Aerobic and resistance exercise improves physical fitness, bone health, and quality of life in overweight and obese breast cancer survivors: a randomized controlled trial. Breast Cancer Res. 2018;20(1):124.

32. Wong CM, Ou CQ, Thach TQ, Chau YK, Chan KP, Ho SY, et al. Does regular exercise protect against air pollution-associated mortality? Prev Med. 2007:44(5):386-92.

33. Dong GH, Zhang P, Sun B, Zhang L, Chen X, Ma N, et al. Long-term exposure to ambient air pollution and respiratory disease mortality in Shenyang, China: a 12-year population-based retrospective cohort study. Respiration. 2012;84(5):360-8.

34. Xu YJ, Gao HL, Liu H, Zhao NW, Cheng Q, Zhang FR, et al. Urinary levels of dimethoate, bisphenol a and benzo[a]pyrene in first-year students of Hohai University from different geographical regions. BMC Public Health. 2021;21(1):1692.

35. Kumar S, Negi S, Maiti P. Biological and analytical techniques used for detection of polyaromatic hydrocarbons. Environ Sci Pollut Res Int. 2017;24(33):25810-27.

36. Pedersen BK, Saltin B. Exercise as medicine - evidence for prescribing exercise as therapy in 26 different chronic diseases. Scand J Med Sci Sports. 2015;25(Suppl 3):1-72.

37. da Silveira MP, da Silva Fagundes KK, Bizuti MR, Starck E, Rossi RC, de Resende ESDT. Physical exercise as a tool to help the immune system against COVID-19: an integrative review of the current literature. Clin Exp Med. 2021;21(1):15-28.

38. RentzT, Wanschel A, de Carvalho ML, Lorza-Gil E, de Souza JC, Dos Santos $\mathrm{RR}$, et al. The anti-atherogenic role of exercise is associated with the attenuation of bone marrow-derived macrophage activation and migration in Hypercholesterolemic mice. Front Physiol. 2020;11:599379.

39. Vieira RP, Toledo AC, Silva LB, Almeida FM, Damaceno-Rodrigues NR, Caldini EG, et al. Anti-inflammatory effects of aerobic exercise in mice exposed to air pollution. Med Sci Sports Exerc. 2012;44(7):1227-34.

40. Yu YB, Liao YW, Su KH, Chang TM, Shyue SK, Kou YR, et al. Prior exercise training alleviates the lung inflammation induced by subsequent exposure to environmental cigarette smoke. Acta Physiol (Oxf). 2012;205(4):532-40.

41. Slowikowski BK, Jankowski M, Jagodzinski PP. The smoking estrogens - a potential synergy between estradiol and benzo(a)pyrene. Biomed Pharmacother. 2021;139:111658.

42. Jakobsen LS, Georgiadis S, Nielsen BF, Bokkers BGH, Boriani E, DuedahlOlesen $L$, et al. Probabilistic approach for assessing cancer risk due to benzo[a]pyrene in barbecued meat: informing advice for population groups. PLoS One. 2018;13(11):e0207032.

43. Tsai KS, Yang RS, Liu SH. Benzo[a]pyrene regulates osteoblast proliferation through an estrogen receptor-related cyclooxygenase-2 pathway. Chem Res Toxicol. 2004;17(5):679-84.

44. Gonzalez-Muniesa P, Martinez-Gonzalez MA, Hu FB, Despres JP, Matsuzawa Y, Loos RJF, et al. Obesity. Nat Rev Dis Primers. 2017;3:17034.

45. Zhong H, Ma M, Liang T, Guo L. Role of MicroRNAs in obesityinduced metabolic disorder and immune response. I Immunol Res. 2018;2018:2835761.

46. Jamnick NA, Pettitt RW, Granata C, Pyne DB, Bishop DJ. An examination and critique of current methods to determine exercise intensity. Sports Med. 2020;50(10):1729-56.

\section{Publisher's Note}

Springer Nature remains neutral with regard to jurisdictional claims in published maps and institutional affiliations.

Ready to submit your research? Choose BMC and benefit from:

- fast, convenient online submission

- thorough peer review by experienced researchers in your field

- rapid publication on acceptance

- support for research data, including large and complex data types

- gold Open Access which fosters wider collaboration and increased citations

- maximum visibility for your research: over 100M website views per year

At BMC, research is always in progress.

Learn more biomedcentral.com/submissions 